\title{
Construction of College English Teaching System based on Computer Network Platform
}

\author{
Baohua Gao \\ School of Foreign Studies, Northwestern Polytechnical University, Xi'an, Shaanxi, 710072, China
}

\begin{abstract}
We should strengthen the construction of computer network platform and construct and perfect the foreign language teaching system. Starting from the talent training system as a whole, it is necessary to establish a scientific and systematic teaching system with ability training as the main line and multi-level, multi-module and interlinked modules, so as to realize online assisted teaching and network and intelligent management and improve the construction of three-dimensional language teaching resources. It is necessary to promote the integration of information technology and foreign language teaching, as well as the optimization and integration of information technology with subject courses and teaching methods, so as to achieve the purpose of strengthening teaching effects and improving teaching quality.
\end{abstract}

Keywords: network platform; Teaching system; Resource construction

\section{I. introduction}

The computer network platform is a resource management platform with digital shared teaching resources built using computer network technology. The platform realizes the informationization and modernization of education by realizing digital teaching and learning and creating virtual learning spaces. Thereby, the original scattered equipment technology, relatively independently operated network audio-visual, language laboratory and teaching software development and production, teaching resources management and control equipment and research experiments and other facilities system constitute a unified organic whole[1-2].

The computer network platform was built to strengthen students' understanding of foreign language courses and to develop their practical skills in a real language application environment, serving as a bridge between theoretical knowledge and practical application. The computer network platform in our college is not only a platform for teaching English, but also an important base for teaching, practicing and researching language in our multidisciplinary and multilingual courses (English, Japanese, Korean, Russian, etc.) in foreign linguistics. It not only undertakes the task of independent study and teaching of college English, but also undertakes the task of teaching practice and research of many specialized courses in foreign linguistics of our college. It is characterized by "large volume, wide coverage and specialization"[3-4].

With the deepening of the reform of college English teaching, the pace of reform in foreign language teaching is also accelerating. The concept, content, methods and teaching methods of the courses offered are constantly being innovated, and the construction of hardware environment such as experimental equipment, experimental conditions and experimental environment is more systematic and scientific. The introduction of advanced science and technology into language teaching has been an inevitable trend in the development of language laboratory teaching. With the help of multimedia network technology, we can create a personalized virtual situation for language learners, so that they can learn and use language in a "real" language environment, and use technology to make up for some shortcomings of traditional teaching, which is an important direction of language teaching reform[5-6].

ISSN: 0010-8189 


\section{Network architecture}

The mainstream networks are now all gigabit networks. The construction of digital language labs as well as independent English learning and online exams will rely on network bandwidth, so the wiring and access switches and core switches are all gigabit devices. The number of clients in our school's language teaching center is relatively large, amounting to about 800 points, and the teacher's machine is about 100 points, which directly accesses the server in the network control center, putting a lot of pressure on the core switching equipment. Therefore, we choose mid- to high-end switches with large backplane bandwidth and large packet forwarding rate, which can make the machines in the whole server room more smooth in accessing the application system on the server without waiting and crashing conditions. We use the network architecture to access the switch and connect directly to the core switch to improve the overall access speed and not to have the state of waiting for the client to open the BS structured application service program to improve the learning efficiency.

In selecting the network core switch, we use a high-density multi-service IPv6 core routing switch for next-generation converged networks to meet the application requirements of Ethernet networks. The switch incorporates multi-service features such as VAU (virtual switching unit), MPLS/VPLS, network security, wireless network, IPv6, and traffic analysis. The rich slot selection leaves abundant room for expansion, forming a converged and unified network. The perfect IPv6 features meet future upgrades and provide a reliable network core support for the networked language experiment center. The access switches adopt full Gigabit electrical ports with strong backplane bandwidth and network stability, providing a good network platform for various teaching applications. The egress routing equipment adopts a network egress device that integrates routing, firewall, behavior management and flow control to control the traffic of devices in the internal network so that the bandwidth can be used effectively. The behavior management function can effectively suppress unreasonable Internet behavior in the LAN and restrain students' Internet behavior in and out of class. The firewall function effectively fends off network attacks on the internal and external networks, while the vpn function of the device provides convenience for teachers' remote work.

The above three devices work together to form a foreign language teaching backbone network and provide a full gigabit, safe and stable campus LAN, and create a good network environment for teachers to handle affairs and students to attend classes. Figure 1 shows the topology diagram of the foreign language teaching network.

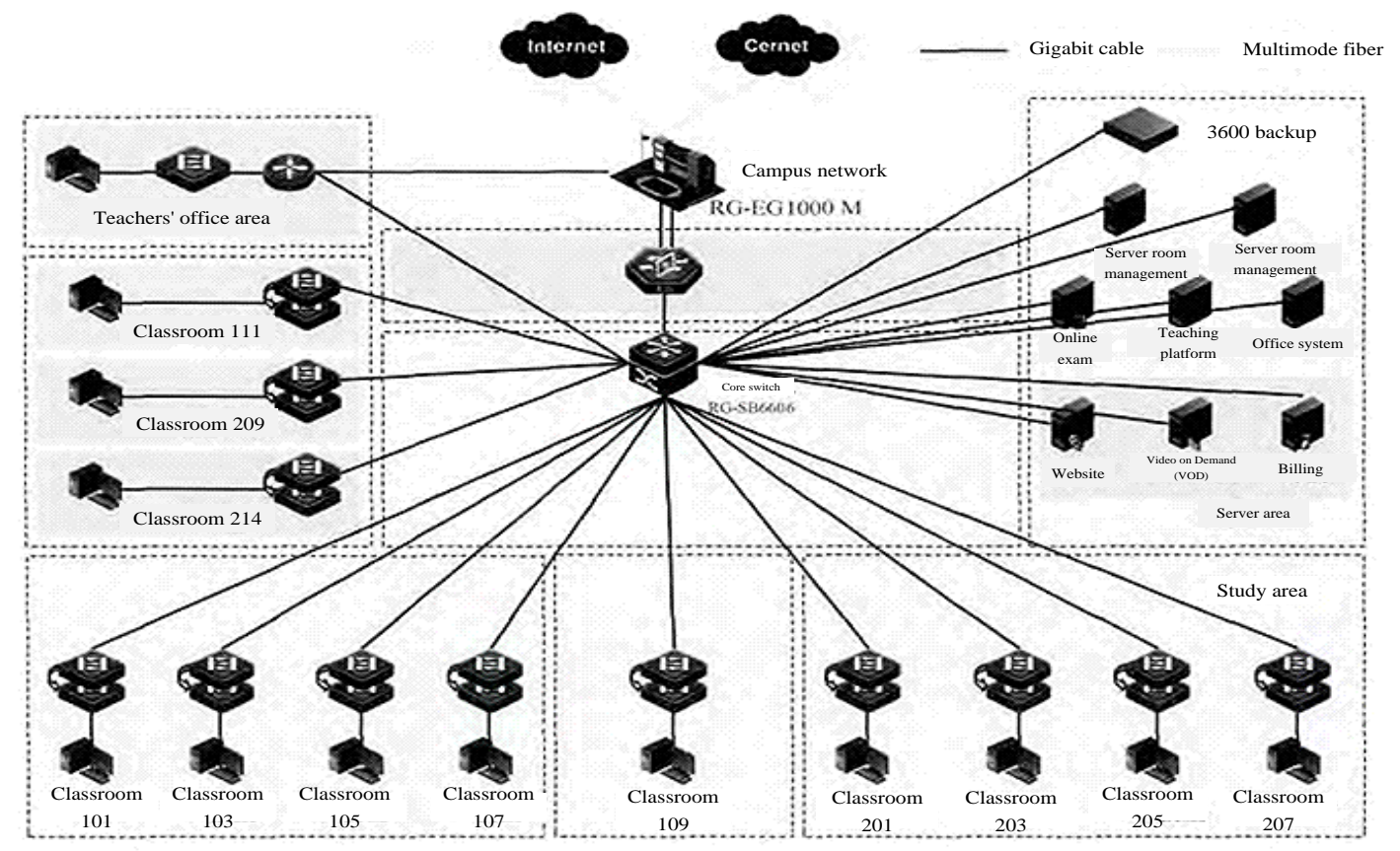

Figure 1. Topology diagram of foreign language teaching network 


\section{Network environment building}

The construction goal of the college English networked teaching platform is to build an advanced, secure, reliable, usable, maintainable, and multi-software integrated platform for course teaching, independent learning, and resource sharing. English teaching based on network information platform can digitize valuable classroom information and collect it in the data center. Students can learn what is taught in class and study independently after class at any time and from any location through computer terminals. These important teaching resources are able to transcend the constraints of time and space and are more freely available to students.

In this platform, teachers can publish teaching resources, teaching materials and answer students' questions synchronously or asynchronously through the Learning System and English Learning Station and the Resource Center. Students can access teaching resources and materials through learning terminals, and complete studies and assignments and submit questions. Students can also communicate with their classmates and teachers through interactive platforms such as blogs and forums. In order to enrich students' independent learning, we have set up "English Online", "New Vision Online", "Online Classroom", "English Learning Station", "Course Support Station", "English Video Station", "VOD Resources", "English Learner Blog”, "English Learner Forum”,"Online English Radio",“Online TV”, “Online Q\&A”,"Intelligent Office System", "Online Monitoring and Evaluation System for Independent Learning of College Students" and other sections .

The online teaching platform of college English (see Figure 2) is composed of "one center and three systems". Through the navigation network of "Dalian college English Teaching and Learning Center", we can access three systems: teaching/learning language resource database system, teaching/learning dual master teaching system and teaching/learning assessment management system. It can realize the personalized cultivation of college students' independent learning, teacher-student network interaction, teaching and learning resources sharing and networked intelligent teaching management .

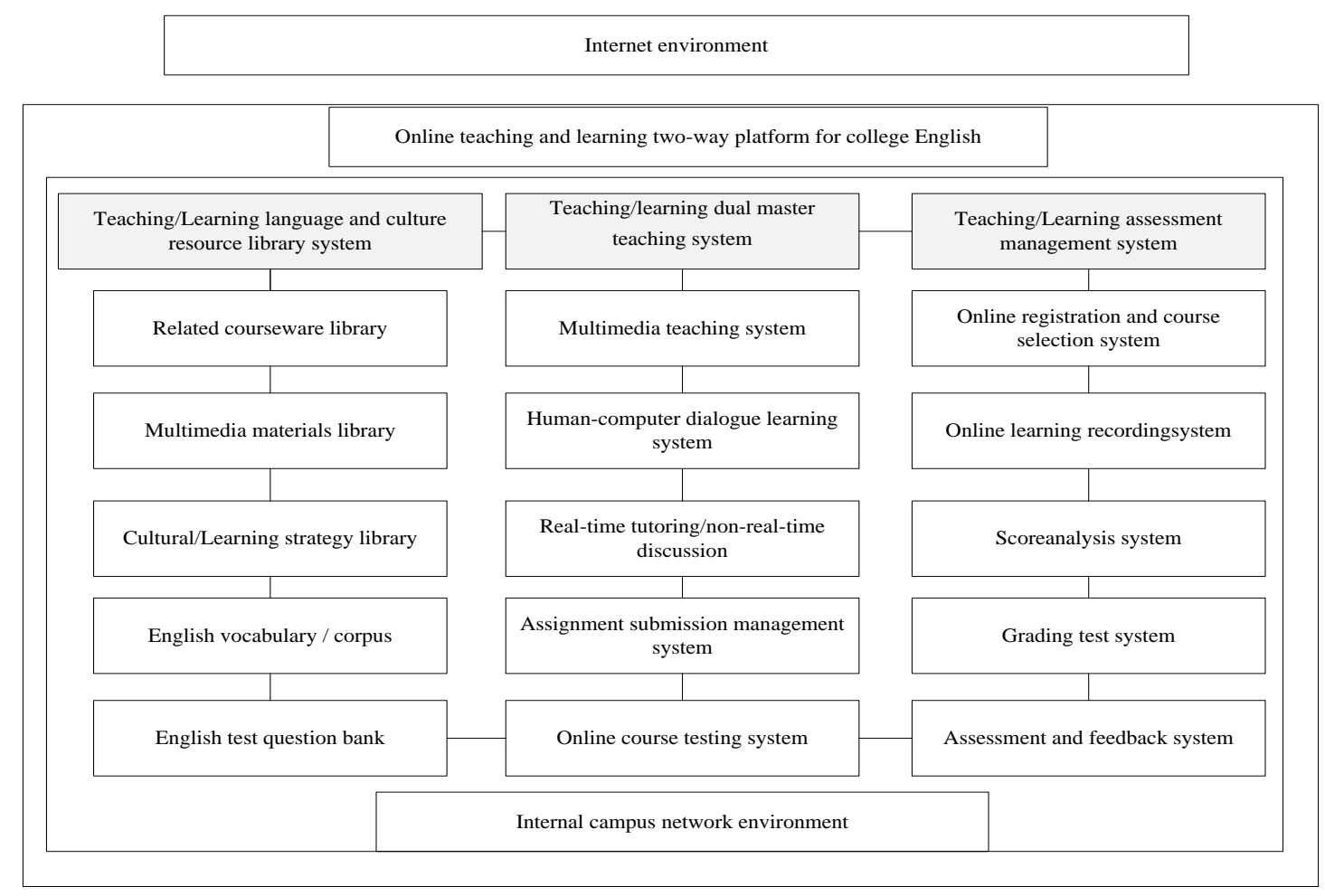

Figure 2. Web-based teaching platform for college English 


\section{IV.The construction of networked teaching system of college English in colleges and universities}

Regarding the construction of the teaching system, based on the student-oriented concept of modern education and instruction, we should establish a new teaching system that is all for the sake of students and suitable for the requirements of professional training objectives of the specialty from three aspects: knowledge, quality and ability. The core of the teaching system is the curriculum system of "basic courses + core courses + special courses", which creates a kind of experimental system that combines scientific spirit and humanistic spirit, emphasizes comprehensive quality, highlights innovation consciousness and practical ability cultivation, and has the function of continuous self-optimization [7]. Computer network platform construction gives full play to network resources and modern information technology to promote the reform of teaching methods and cultivate a new concept of language learning. In the formation of the computer network platform and the development of teaching construction planning, the experimental course system and experimental content should be further integrated and optimized, and the teaching methods and means should be reformed in order to gradually realize the transition from teacher-led to student-led learning and to reflect the modernization, informatization, and synthesis of teaching content [8].The purpose of establishing a practical teaching system is to enhance students' understanding of the practical application of foreign languages, to exercise their coordination, communication and comprehensive application of theoretical knowledge, and to cultivate their professionalism.

\subsection{The idea and plan for building a teaching system}

Aiming at quality-oriented education, a new teaching system of college English language teaching should be constructed. With the reform of teaching content as the breakthrough point, we should pay attention to the integration of language experiment and modern science and technology. Taking the digital network environment as the teaching management means, we should create a diversified teaching environment for the cultivation of innovative talents. In the teaching management system, the emphasis should be placed on the construction of college English teaching and language teaching system based on network and computer, so as to enrich the teaching content. We should focus on the construction of networked teaching system to improve students' ability and interest in independent learning. We should adhere to the concept of large-capacity open teaching, and at the same time of expanding the capacity, complete the transformation from closed to open, and highlight the establishment of comprehensive and designed experiments.

College English is a very important course in cultivating students' application ability. College English is a basic compulsory course for non-English majors. This course aims to cultivate and improve students' comprehensive quality, enable them to have the ability of intercultural communication and academic communication, and enhance their potential for academic research and development.The main teaching contents of college English are language knowledge and skills, learning strategies, intercultural communication, creativity and critical thinking. Its teaching goal is to cultivate students' comprehensive English application ability, especially their listening and speaking ability, enhance their independent learning ability and comprehensive quality, and create conditions for them to conduct cross-cultural communication, international academic exchange and lifelong learning. The specific plan is as follows:

(1) Build a sufficient number of college English independent learning machines to meet students' independent learning needs and cultivate students' personality development. At present, our university has built a university English independent learning center consisting of 813 computers, which is open to students until 9:00 p.m. every day (including weekends), but we have to continue to build it to meet the needs of students' independent learning and English teaching [9].

(2) Building a massive English learning resource library to meet students' English learning needs at all levels and degrees. The English Teaching Experiment Center of our university has built a massive English learning and teaching resource library system consisting of 10 servers, with a total of more than $2000 \mathrm{G}$ of text, audio, video and 
multimedia resources, but it needs to continue to be built, such as adding more servers .

(3) Build a variety of network platforms to realize the network interaction between teachers and students. At present, our university has built "English Online", "New Vision Online", "Online Classroom", "English Learning Station ", "VOD resources", "English learners' blog", "Internet English radio", "Internet TV Station", "Intelligent Office System" and other interactive web platforms.

(4) Establish a monitoring and evaluation system for online independent learning to ensure the healthy development of students' independent learning in college English. Monitoring and evaluation of network independent learning is an effective way to ensure the smooth progress of independent learning and the correct evaluation of students' learning. We have successfully built the "network monitoring and evaluation system for college students' independent learning", but it still needs to be improved.

(5) Network office automation is a guarantee for realizing independent learning of college English in the network environment and for teachers to change their roles. We have built a web-based office automation website for the College of English to realize networked and instant teaching management, which has improved the efficiency and accuracy of teaching management.

(6) Theindependent online learning is planned, arranged and evaluated. 1 class hour per week of online independent learning under the guidance of teachers in the freshman year +3 class hours of free independent learning after class; In the sophomore year, 3 hours of free independent study per week. Network management is recorded and guided throughout the process.

\subsection{Main features of the teaching model}

The reform enables teachers to keep track of students' learning and psychological dynamics at the right time. Not only does it make students comfortable and convenient to choose their courses, but also allows them to feel that the laboratory, laboratory teachers and various teaching resources are close to them no matter where they are. The smooth communication brings good experimental results and creates conditions for improving students' practical skills. Moreover, a special laboratory is established .

The teaching model should have the following features:

(1) It reflects the development of English teaching towards personalized learning, independent of time and place, and active learning, supported by modern information technology, especially network technology.

(2) It reflects the principle of integration of practicality, culture and fun of English teaching. It should be able to fully mobilize the enthusiasm of 2 parties, teachers and students, especially to establish the main position of students in the teaching process.

(3) In terms of technology, it embodies interactivity, achievability and ease of operation.

(4) It allows students to choose the right material for their study anytime and anywhere. Students are able to complete listening and speaking training that cannot be done in traditional classrooms, while teachers are able to record, understand and test students' learning as well as teachers' teaching and tutoring at any time. Thus, it can urge students to study actively, promote a faster improvement of students' English listening and speaking ability and other practical abilities, and promote the formation of students' personalized learning methods and the development of students' independent learning ability.

The establishment of this teaching model is not just a change in teaching activities or teaching methods, but a change 
in teaching philosophy. It is a change from a teacher-centered teaching model that simply imparts language knowledge and skills to a student-centered teaching model that imparts general language knowledge and skills, but also focuses on developing language use and independent learning skills.

\section{Conclusion}

The construction of computer network platform should be based on the practical teaching construction concept of equipment construction, network improvement and network online management as a whole, highlighting the cultivation of students' English application ability. A multi-level network platform coupled with a huge amount of network resources constitutes a computer network platform for cultivating personalized talents. A three-dimensional language practice, open and interactive English learning style should be established to extend the teaching content of the first classroom into the language practice of the second classroom. Through the network independent learning mode, it reflects that the teacher is no longer the only source of knowledge for students, and the podium is no longer the only stage for teachers to face students. In this way, students can acquire language communicative competence in the cycle of "participation", "competition", "success" and "confidence" to "participation again", "competition again", "success again" and "more confidence". At the same time, quality education can be realized in an all-round way.

\section{Reference}

[1] Xiao Shengyang. Research on project teaching method in computer course teaching [j]. Research on computerization education, 2003

[2] Pujiang, Jiao binglian. Construction and application of computer network course teaching platform based on Moodle [J]. Journal of Xuzhou Institute of Engineering (NATURAL SCIENCE EDITION), 2011 (04): 39-42

[3] Zhao Sijia, Yin Ting, Zhao OSI Jia, et al. Construction of computer network course teaching platform based on Packet Tracer simulator [J]. Hunan Journal of Ecological Sciences, 2010, 16 (1): 15-18

[4] Tian Chao. Design of bilingual teaching platform for computer network course based on MySQL [D]. Inner Mongolia University, 2016

[5] Jiang Ning, Yang Shu, Yang Xuehua. Cloud Computing Assisted Instruction Platform Based on Zoho wiki [J]. JOURNAL OF SHENYANG NORMAL UNIVERSITY (NATURAL SCIENCE EDITION), 2012, 30 (002): 232-235

[6] Dong Hongxue, Zhang Kunyuan. Research on MTI Translation Workshop Teaching Mode under cloud computing learning platform [J]. Foreign language audio visual teaching, 2016, 000 (001): 56-61

[7] Jiang Ning, Li Wen, Li Hongbin. Research on Cloud Computing Assisted Instruction Platform Based on Hadoop [J]. China distance education, 2012, 000 (017): 79-82

[8] Cui Zhongwei, Deng Yanling, Zuo Yu. Application of mainstream Cloud Computing Assisted Instruction Platform in national training program [J]. Internet of things technology, 2015, 5 (12): 97-99 